\title{
Implementation of PE Teaching Method under Innovative Educational Concept
}

\author{
Liguo Zheng \\ Taishan Medical University, Tai'an, 271000, China
}

Keywords: Innovative educational concept; Physical education; Method; Implementation

\begin{abstract}
With regard to physical education cause in China, with the constant deepening of educational reform and the combination of theory and practice in the development path in recent years, innovative physical education has become a new direction in the current education cause. Meanwhile, it is an effective approach to realize the demand for high-quality comprehensive talents in the society. Therefore, PE method cannot be fixed and should develop further with the step of innovative educational concept. On this basis, this paper mainly discusses the implementation of PE method under innovative educational concept.
\end{abstract}

\section{Introduction}

The reform of PE method puts more emphasis on the combination of educational theory and practice and the transformation from singleness to comprehensiveness. Innovative education is an extension, expansion and deepening of quality-oriented education as well as an important approach to train high-quality creative talents. Education is the main base for cultivating higher and professional talents in China. Adapting to and satisfying the social demand for new talents is an important starting point of Chinese educational reform. As an essential component of education, educational concept and method influence the development of students first and then affect the development of the overall education cause in China to a great extent. Therefore, to achieve certain development and new breakthrough, PE teaching is inseparable from new educational theory and concept. PE teaching is beneficial to students because it can improve their physical quality and make them abandon bad living style. Meanwhile, it plays a vital role in the training of students' consciousness of innovation and thinking. Therefore, PE teachers should follow the pace of innovative education and take various teaching means under innovative concept to realize new breakthrough in PE teaching practice.

\section{Overview on PE method under innovative educational concept}

Innovative education refers to new extension and development in the original quality-oriented education. Innovative education refers to the education training students' awareness and ability of innovation, promoting their integrated development and carrying forward the subject spirit of human. It is a required approach to train high-quality versatile talents.

Physical education method with a special status makes it fail to have a clear definition under the argument of many scholars. However, after comparing some definitions of physical education method made by relevant scholars and experts, we think that physical education methods without definition or final conclusion have three common points: first, they are specific educational means or methods taken to achieve specific educational objectives; second, teaching activities are interactive and teachers and students need to interact; third, PE method is not simply a single and rigid method and students' learning and activities should be included.

PE teaching method should be the complex of these common points above under the guidance of innovative educational concept. Currently, there are different classification methods under innovative educational concept. Some use teaching principle, teachers' and students' role or information perception approach as the classification standard. All classification methods have certain reason. These methods can give us some inspirations more or less to a certain extent. 


\section{Status quo of PE teaching in the current stage}

With the constant improvement of Chinese cultural soft power and the deepening of educational reform in recent years, corresponding teaching methods have changed gradually. Chinese education attaches more importance to the training of creativity. This lays a foundation for the training of versatile talents. PE teaching is an important constituent part of basic education and its method plays a vital role in the improvement of the physique and quality of the nation. However, PE teaching process is not always smooth. There are some difficulties and challenges that cannot be overcome easily. The traditional physical education method is still adopted in most regions in China currently. Importance is attached to students' sports skill and physical quality, which is good. However, there are some deficiencies. For example, teachers neglect the connotation of physical education in teaching and show no interest in students' feeling. Students only conduct simple and mechanical training passively in the teaching process. They easily feel bored, thus causing non-ideal training result.

The national education department have kept pace with the times and gradually found various deficiencies in education. It starts to attach importance to students' consciousness of innovation and reform the traditional physical education under the guidance of innovative education. This produces certain influence on the quality and efficiency of education. Influenced by innovative teaching method and new teaching equipment, students' interest and enthusiasm are aroused and their mind and body can be exercised effectively. Moreover, they change their way of thinking unconsciously. However, there are certain difficulties in the evolution from the old one to the new one. Students cannot get rid of the influence of traditional teaching concepts and might be unadapted to or resist teachers' teaching in a new form, especially in those areas with backward development and old equipment or the lack of teaching equipment. This undoubtedly hinders the good combination of theory and practice.

In addition, the main function of PE class is to improve the physique of students. Any other function of PE class must be based on this function. This becomes a requirement of the current innovative education. However, according to the investigation on the current status of PE class in China, PE class has very few functions. It even fails to realize the basic function of improving students' physique, let alone other senior functions. The current PE class is fuzzy on the whole. For example, there is no special PE textbook. Therefore, what should be taught and to what extent the teaching should be are fuzzy points of PE class. Teachers teach students stereotyped contents with obsolete methods to maintain the insurance of physical education and neglect innovation. Therefore, teachers dare not make a breakthrough while facing innovation and students resist and hate PE class, thus causing the decline of PE teaching quality.

\section{Implementation of PE teaching method under innovative educational concept}

\section{Deepen innovative physical educational concept}

The failure to form a relatively perfect and reasonable methodology in the situation of physical education is caused by the obsolete and simple mode of physical education which lacks theoretical guidance on students to a great extent. Physical education under the traditional mode only attaches importance to students' sports skills. Such educational system fails to meet the demand of social development. The emergence of innovative educational concept undoubtedly becomes a good recipe or guiding light for making up for and improving the old mode of physical education. This makes numerous PE teachers realize that learning quality is mostly influenced by teaching method and implement teaching with a free teaching method on this basis. Influenced by this new concept, PE teachers have full understandings of the position of students in PE teaching and further organize problems existing in teaching method and mode to a certain extent. Therefore, this force promotes the step of educational reform. The main object of innovative educational concept is students. Relevant national departments of education expect schools to deepen the educational reform under the 
guidance of this new concept and theory and positively encourage students to finally achieve personalized development rather than using negative evaluation method for students. This also provides an opportunity for teacher-student interaction and communication. A new PE teaching method will be established under the joint effort of students and teachers, which can guarantee the quality of physical education unprecedentedly, improve the efficiency of physical education and make it satisfy the development demand of social talent training mode. In addition, the effective combination of theory and practice of PE teaching is also achieved under this new concept. As long as this new educational concept is used as the guiding concept of physical education mode and constantly practiced and improved, it can win the recognition and understanding of more students.

\section{Optimize the setting of PE course}

First, teachers must abide by certain design principles in the designing of classroom teaching and consider whether the course meets students' physiological features and is interesting, systematic and pertinent. Moreover, to allow students to learn the course smoothly, teachers must first make students interested in the course. To make students interested, teachers must try every means to attract their attention. Therefore, good design of PE classroom is extremely important. Second, students are the subject of education. Teachers should guide them to the best of their potential. For example, teachers can make students happy and relaxed in class with diversified methods. However, attention should be paid not to bring personal emotion to the class when a method is used, e.g. academic result and kindred. If PE teacher divides the education according to the academic result of students, it will greatly reduce the interaction between teacher and students and widen the emotional distance. Teachers should make students realize that PE class is equal and free and filled with joy. Therefore, teachers' guidance on the harmony of the whole class and each student' s interest in the class is indispensable. Moreover, parents regard their own children as dearly loved person and spoil them in the current society. Such children have a low ability of coping with setbacks and their negative emotion easily influences their mind and body. Therefore, PE teachers should help students have a correct understanding of setbacks in physical exercise and realize that success or failure is not that important. Teachers' guidance on students is helpful for their future. Third, entertainment is essential in class. Sport is joyful. However, the current classroom setting is too normative, which results in the loss of essential effect of sports. Therefore, to improve students' initiative in sports, it is required to set up a course showing the essence of sports. Only in this way can students exercise actively and initiatively and achieve the purpose of body exercise and smooth implementation of teaching objectives.

\section{Strengthen the supervision on PE class}

With respect to curriculum setting, the Ministry of Education transfers its order to schools periodically. However, some schools violates the order publicly mainly due to the lack of strong supervision on the setting of PE course. Moreover, many schools think that higher enrollment rate is useful for the building of their reputation and PE class is of no importance and necessity. For such behavior of schools, it is required to strengthen the supervision so as to reduce such bad behaviors and guarantee the due sports time of students to a certain extent. It is necessary to improve the policy and strengthen the publicity - on the one hand, implement hard policies to guarantee practical setting of PE class; on the other hand, make strong publicity so as to spread PE teaching concept under innovative concept and solve problems of this new mode more effectively and easily.

\section{Pay attention to the comprehensiveness in $\mathrm{PE}$ teaching process}

PE teaching should not be single and obsolete and should be updated. Attention should be paid to its comprehensiveness. That is to say, it is required to develop and create new theory constantly in PE teaching and guide practical teaching activities on this basis; implement it from teaching objectives and facilities and in more aspects, consider various factors of teaching carefully, constantly improve its attention with the combination of theory and practice and help students build a correct consciousness of learning initiatively. 


\section{Innovate the evaluation system of PE teaching achievements}

As the main function of evaluation system of PE teaching achievements is to evaluate the learning status of students, the rationality of its evaluation means and method concerns the initiative of students in study. Therefore, the innovation of this system is essential. The original means and method can be improved so as to promote the comprehensive development of students.

\section{Conclusion}

In conclusion, PE teaching method will be more diversified and be implemented more effectively under the guidance of innovative concept. It is difficult to embody its advantages more significantly with one' s own effort alone. Therefore, the cooperation of multiple parties is required, such as school and society. Only with the constant cooperation and efforts of school, society and teachers can innovative education achieve its objectives and PE teaching effect be realized fully under this concept.

\section{References}

[1] Zhang Wenbo. Discussions on Theory and Practice of PE Teaching Method under Innovative Educational Concept. Sports Goods and Technology, 2014,(09).

[2] Huo Jun. Research on Theory and Practice of PE Teaching Method under Innovative Educational Concept [J]. Beijing Sport University, 2014,(05).

[3] Yang Weihua, Guo Yunbing. Research on PE Teaching Method and Practice under Innovative Concept. Contemporary Sports Technology, 2013,(23).

[4] Ibrahim Ashat . Research on Theory and Practice of PE Teaching Method under Innovative Educational Concept. Chizi (Midmonth), 2013,(15).

[5] Ji Weilong. Exploration and Analysis on Evolution and Development of PE Learning Method in PE Teaching Design in Primary and Middle Schools - Overview on Research Literatures on PE Learning Methods in Primary and Middle Schools Published from 2001 to 2011. Sports Scientific Literature. 2011,(10) .

[6] Cai Shikai. Investigation and Experimental Study on Application of "Independent Investigation-Cooperation” PE Teaching Method in PE Teaching in Middle Schools. East China Normal University, 2006. 